\title{
Feasibility of Biochar Preparation with Solar Pyrolysis Method
}

\author{
Huihong Luo ${ }^{1}$, Shaohong Chen ${ }^{1}$, Jie $\mathrm{Li}^{1}$, Xiaoting Hou ${ }^{1,2}$, Nuo Chen ${ }^{1}$, Haipeng Lan ${ }^{1}$, \\ Dongyong Cai ${ }^{1}$, Qia Chen ${ }^{1}$, Xiaoyin Yang ${ }^{1}$, Sitian Zhang ${ }^{1}$ and Changsheng Peng ${ }^{1, *}$ \\ ${ }^{1}$ School of Environmental and Chemical Engineering, Zhaoqing University, Zhaoqing 526061, China \\ ${ }^{2}$ The Key Lab of Marine Environmental Science and Ecology, Ministry of Education, Ocean \\ University of China, Qingdao 266100, China;
}

\begin{abstract}
China is a large agricultural country with a large annual output of straw resources. Compared with other straw treatment technologies, pyrolysis technology has the advantages of simple operation and high utilization value of products, but the traditional pyrolysis technology takes the combustion of fossil fuels as heat source, which has the problem of high energy consumption. Solar pyrolysis has attracted much attention because of its cleanliness and sustainability. To explore the feasibility of solar pyrolysis of straw. In this paper, the corncob biochar prepared by solar pyrolysis device and traditional pyrolysis device (muffle furnace and tube furnace) were compared. The experimental results show that the solar pyrolysis device can reach the pyrolysis temperature range of biomass, and the yield and physicochemical properties of the biochar obtained by the solar pyrolysis device are similar to those obtained by the traditional pyrolysis device. Therefore, the preparation of biochar by solar pyrolysis is a feasible method.
\end{abstract}

\section{Introduction}

Biomass energy is the fourth largest energy that can be used on the earth. Biomass includes lignocellulose such as trees produced in the process of agricultural and forestry production, scraps of agricultural products processing industry, agricultural and forestry wastes and livestock manure and wastes in the process of animal husbandry production[1]. As a large agricultural country, China has an annual straw output of 700 million tons, accounting for about $20 \%$ of the world's total[2,3]. At present, the main utilization methods of straw include direct return to the field, use as feed, direct incineration, anaerobic biogas, pyrolysis, etc. Among them, direct returning to the field is a common method, but if the straw cannot be fully buried and covered, it cannot better achieve the agronomic requirements of returning to the field, and even affect the growth of crops[4]. Generally, the physical properties of straw are changed by chopping, soaking, cooking, high-pressure steam treatment and other methods for feed, but the utilization rate of straw is low, and its application and promotion is limited[5, 6]. Direct incineration is banned by the state because it produces a large amount of greenhouse gases, smoke and dust (PM2.5, PM10

* Corresponding author: pcs005@sohu.com 
polycyclic aromatic hydrocarbons, dioxins, etc.), which is easy to cause air pollution and threaten human health[7,8]. Anaerobic biogas production is a process in which a variety of microorganisms are used to degrade straw into biogas under anaerobic conditions and produce by-product biogas liquid and biogas dregs. Microorganisms have poor ability to degrade cellulose, hemicellulose and lignin, the main components of straw. The energy output rate of anaerobic biogas is not high, which limits its popularization and application[7, 9].

Pyrolysis refers to the thermal degradation of biomass or organic matter under anaerobic or oxygen-limited conditions, resulting in biochar, volatile condensable substances (such as wood vinegar and tar) and gaseous products (such as $\mathrm{H}_{2} \mathrm{O}, \mathrm{CH}_{4}, \mathrm{H}_{2}, \mathrm{CO}_{2}, \mathrm{CO}$ )[10]. The biochar produced by pyrolysis can also be used to improve soil fertility, improve resource utilization efficiency, reduce environmental pollution and greenhouse gas emissions, etc., so this method has the advantages of simple operation and high economic benefits compared with other methods of treating straw[11]. However, at present, the commonly used pyrolysis method is mainly through the combustion of fossil fuels as heat supply, which has some problems, such as high energy consumption, large greenhouse gas emissions[12]. How to improve the existing pyrolysis technology to achieve efficient resource treatment of straw is an urgent problem to be solved. In this experiment, corncob biochar was prepared by solar pyrolysis decieve and compared with the biochar prepared by traditional pyrolysis equipment muffle furnace and tube furnace to explore the feasibility of preparing biochar by solar pyrolysis.

\section{Materials and methods}

\subsection{Experimental materials}

The corncob (from Anshan, Liaoning Province) was dried for 12 hours to constant weight in an electric blast drying box (Shanghai Jinghong Experimental equipment Co., Ltd.). The pyrolysis experiments of dried biomass were carried out in solar pyrolysis device and traditional pyrolysis device respectively (Fig.1). As shown in Fig.1a, the solar pyrolysis device (from Shandong Huangming Solar Energy Co., Ltd.) is mainly composed of three parts. The first part is that the solar concentrator is a trough concentrator, its function is to collect the solar light and transfer it to the tubular reactor to achieve the effect of heating. The tubular reactor is the pyrolysis place of biomass, which has two-layer structure, the outer layer is quartz glass tube, the inner layer is metal copper tube coated with light-absorbing material, and there is a vacuum between layers. This design structure greatly improves the efficiency of photothermal conversion. The third part is the solar tracking system, which is composed of a photosensitive resistor and a power plant. When the photosensitive resistor senses sunlight, it will transform the light signal into an electrical signal to the power plant to react and adjust the device to achieve the best pyrolysis conditions. During the solar pyrolysis experiment, the solar power meter (from Shenzhen Xinbaorui instrument Co., Ltd.) and the thermocouple thermometer (from Youlide Technology Co., Ltd.) were used to record the solar radiation intensity and the temperature in the tubular reactor. The traditional pyrolysis equipment uses vacuum tube furnace (from Shanghai Shengli Test instrument Co., Ltd.) and muffle furnace (from American Neytech). 


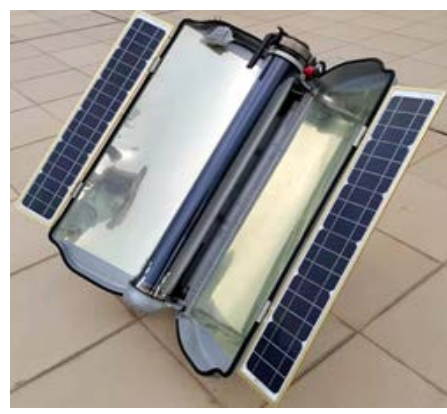

a. Solar pyrolysis device

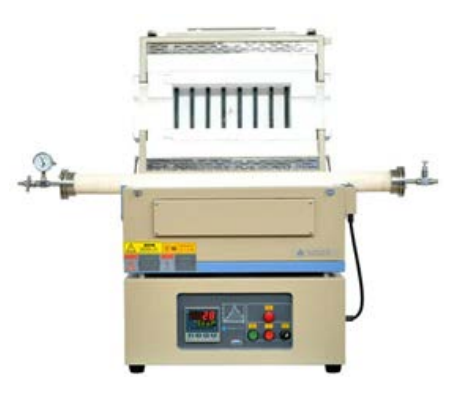

b. Tube furnace

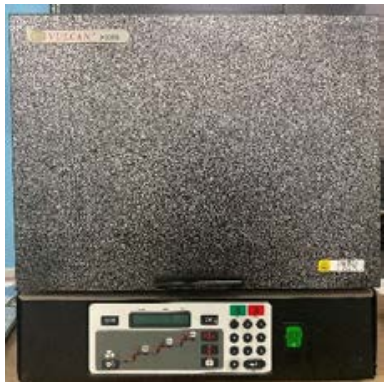

c. Muffle furnace

Fig.1. Pyrolysis device. (a) Solar pyrolysis device. (b and c) Traditional pyrolysis device.

\subsection{Biochar preparation}

The corncob dried to constant weight was weighed, and the pyrolysis experiments were carried out by solar pyrolysis device, tube furnace and muffle furnace respectively. The steps of pyrolysis of corncob by solar pyrolysis device are as follows: in fine weather, place a solar pyrolysis device in a wide area with sufficient sunlight, put a corncob (mass $\mathrm{M}_{1}$ ) into the tubular reactor for pyrolysis, and record the solar radiation intensity and pyrolysis temperature every five minutes Solution temperature. After the pyrolysis is over, move the equipment to a cool place and wait for the temperature in the reactor to cool to room temperature. Take out the solid remaining material after pyrolysis and weigh it (mass is $\mathrm{M}_{2}$ ) and store it. The steps of corncob pyrolysis in tube furnace and muffle furnace are as follows: in each group, a corncob (mass $\mathrm{M}_{1}$ ) was put into the pyrolysis reactor, the target final temperature was set at $250^{\circ} \mathrm{C}, 300^{\circ} \mathrm{C}, 350^{\circ} \mathrm{C}$, and the heating rate was $4^{\circ} \mathrm{C} / \mathrm{min}$, to keep the target temperature for $1 \mathrm{~h}$. The corncob biochar obtained by pyrolysis is weighed (mass $\mathrm{M}_{2}$ ) and stored.

\subsection{Yield and characterization of biochar}

The yield of biochar refers to the mass ratio of solid products to raw materials after biomass pyrolysis, and its calculation formula is

$$
X=\frac{M_{2}}{M_{1}} \times 100 \%
$$

In the formula, $\mathrm{X}$ is the yield of biochar, $\%, \mathrm{M}_{2}$ is the mass of solid product obtained after pyrolysis, g., $\mathrm{M}_{1}$ is the mass of corncob, $\mathrm{g}$.

The structure of biochar was observed by field emission scanning electron microscope (SUB8200, HITACHI), the thermogravimetric analysis of raw materials was carried out by thermogravimetric analyzer (TG209F3, Tarsus), and the thermogravimetric curve was observed, and the DTG curve was obtained by differential thermal analysis, which was used to characterize the change rate of raw materials with temperature and time. XRD spectroscopy was used to analyze the effects of different preparation methods on the crystal structure and carbonization mechanism of biochar. The infrared spectrum of the structure of organic functional groups in biochar was determined by Fourier transform infrared spectrometer, and the species and richness of functional groups in biochar were analyzed. 


\section{Results and discussion}

\subsection{With TGA and DTG of Corncob}

The TG and DTG curves of the corncob are shown in Fig.2. As can be seen from the diagram, the pyrolysis process of corncob can be divided into three stages. The first stage is the drying and dehydration stage $\left(30^{\circ} \mathrm{C}-100^{\circ} \mathrm{C}\right)$, in which water and some volatile substances are volatilized, and the second stage is the main pyrolysis stage $\left(200^{\circ} \mathrm{C}-350^{\circ} \mathrm{C}\right)$, in which cellulose, hemicellulose and lignin in biomass are decomposed to produce a large amount of volatile matter, in which the weight loss rate is the highest and the curve is the steepest. The third stage is the carbonization stage (after $350^{\circ} \mathrm{C}$ ), the biomass is further pyrolyzed and carbonized, and the pyrolysis weight loss rate decreases.

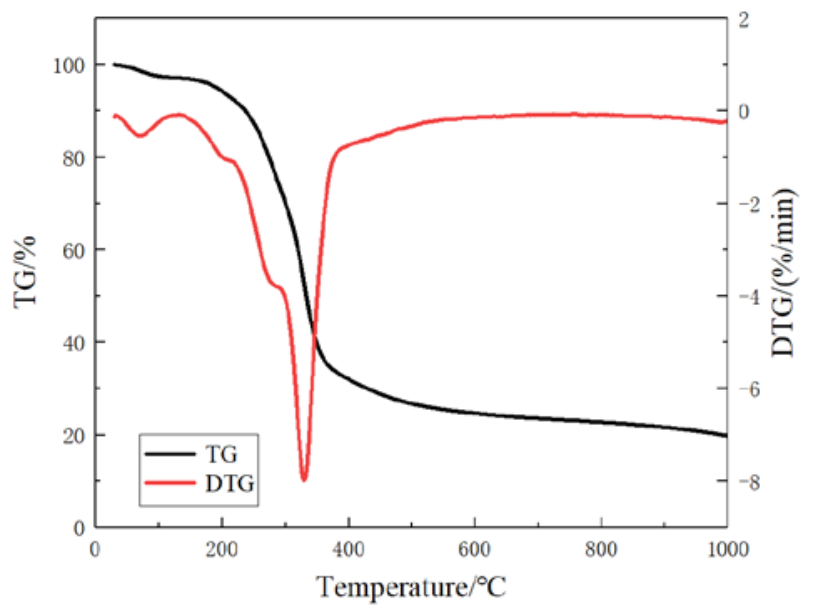

Fig.1. TG-DTG curve of corncob

\subsection{Effect of solar irradiation intensity on solar pyrolysis temperature}

Fig.3 shows the variation curves of solar radiation intensity and pyrolysis temperature during the preparation of biochar by solar pyrolysis in Zhao Qing City, Guangdong Province in September and November, respectively. As shown in Fig.3, the average solar radiation intensity in different months can reach $1000 \mathrm{~W} / \mathrm{m}^{2}$, but the pyrolysis temperature in November is lower than that in September. The reason for this result may be due to the difference in external ambient temperature. The average low temperature in Zhao Qing is $23^{\circ} \mathrm{C}$ in September and $15^{\circ} \mathrm{C}$ in November. According to the comparison of ambient temperature, it can be found that the solar radiation intensity is not much different. The external ambient temperature has a great influence on the pyrolysis temperature. Although the solar pyrolysis equipment is greatly affected by the ambient temperature, the pyrolysis temperature is in the range of $250^{\circ} \mathrm{C}-400^{\circ} \mathrm{C}$, the heating rate is in the range of $3-5^{\circ} \mathrm{C} \mathrm{min}^{-1}$, and the duration of the pyrolysis process is about $1 \mathrm{~h}$. The results of 2.1 thermogravimetric analysis show that the pyrolysis device meets the conditions needed for biomass pyrolysis. 

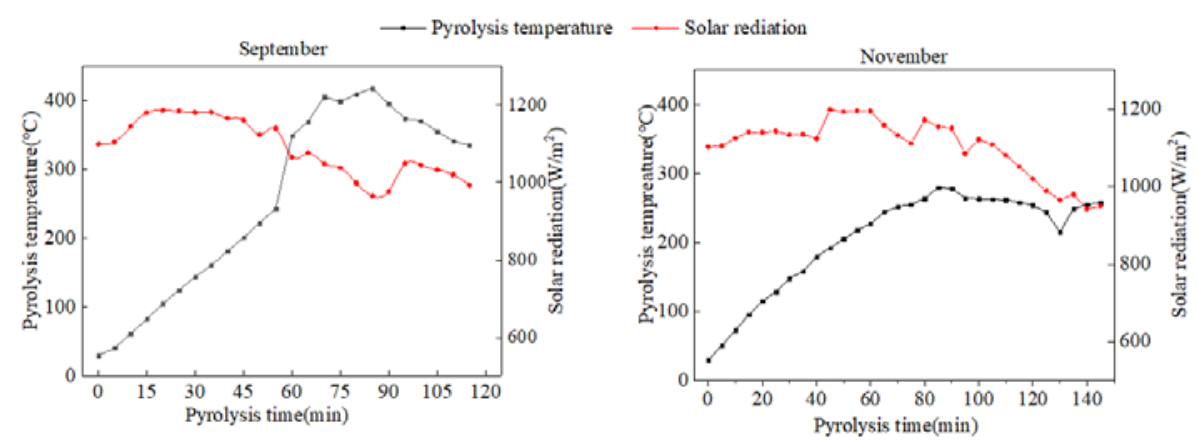

Fig.2. Solar radiation intensity and thermal solution temperature relationship graph

\subsection{Comparative assessment of production yield of pyrolysed product}

As shown in Fig.4, the biochar yield decreases with the increase of pyrolysis temperature, which is similar to the results of Wu et.al[13].

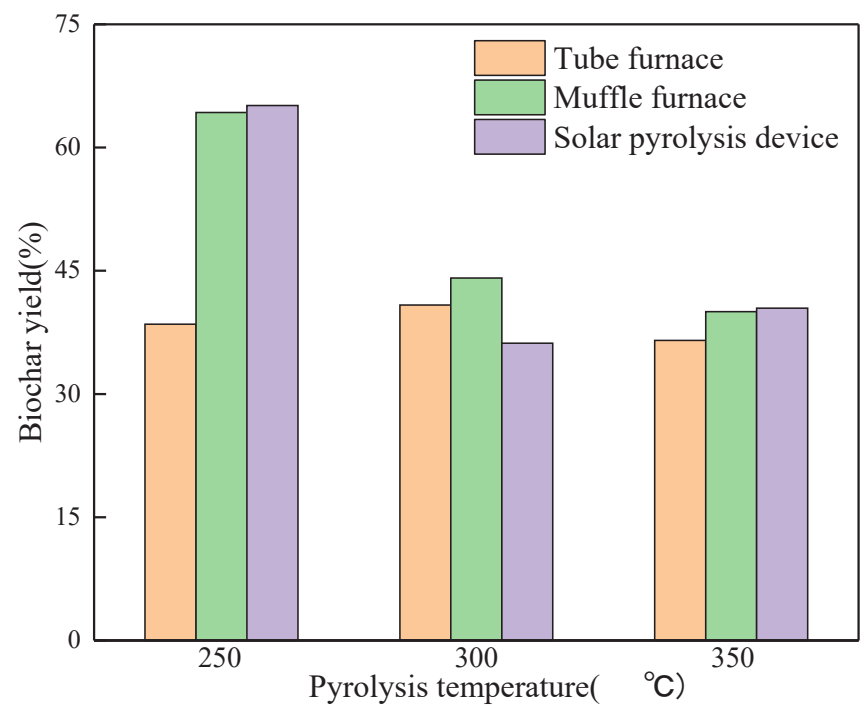

Fig.3. Diagram of biochar yield at different temperatures in different devices

When using tube furnace pyrolysis, the yield is $45.49 \%, 40.83 \%$ and $36.53 \%$ respectively; when using muffle furnace pyrolysis, the yield is $64.27 \%, 44.12 \%$ and $40.02 \%$ respectively; when using solar pyrolysis device, the yield is $65.12 \%, 40.44 \%$ and $36.19 \%$, respectively. On the whole, the yield of biochar from vacuum tube furnace changed little with temperature, but the change of biochar yield from muffle furnace was similar to that from solar pyrolysis device, and decreased obviously in the temperature range of $250^{\circ} \mathrm{C}$ $-300^{\circ} \mathrm{C}$. The yield of biochar obtained from vacuum tube furnace is similar to that from vacuum tube furnace in the range of $300^{\circ} \mathrm{C}-350^{\circ} \mathrm{C}$. 


\subsection{Scanning electron microscope (SEM) Analysis of biochar}

In order to explore the effect of solar pyrolysis device on the morphology and structure of biochar prepared at different temperatures, the biochar prepared at the original, $250^{\circ} \mathrm{C}$ and $350^{\circ} \mathrm{C}$ solar pyrolysis temperatures were analyzed by scanning electron microscope (SEM). As shown in Fig.5, the surface of corncob before pyrolysis is smooth, and pores begin to appear on the surface of biochar at $250^{\circ} \mathrm{C}$. With the increase of pyrolysis temperature to $350^{\circ} \mathrm{C}$, the micropore structure is obvious and widely distributed. The reason for this phenomenon is that cellulose, lignin and hemicellulose decompose with the increase of pyrolysis temperature and produce multi-pore structure.

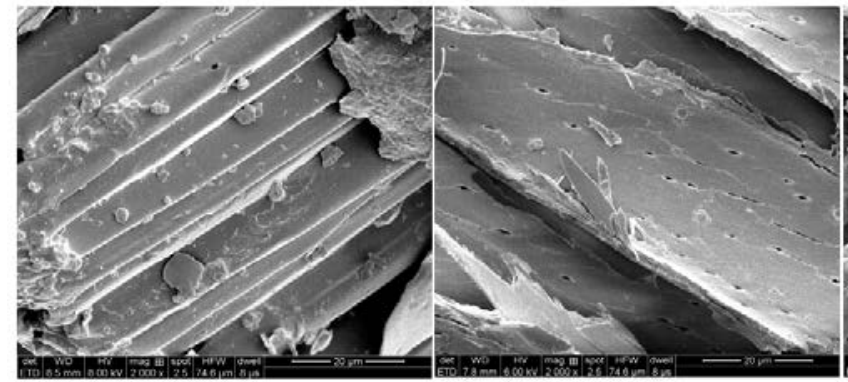

(a) Original from

(b) $250^{\circ} \mathrm{C}$

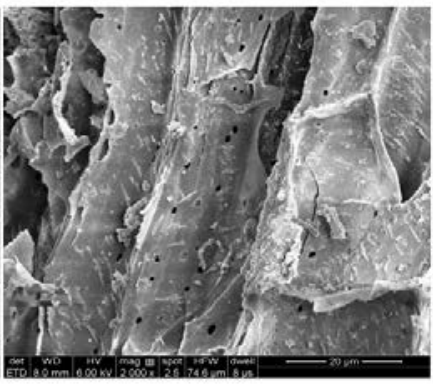

(c) $350^{\circ} \mathrm{C}$

Fig.4. Scanning electron microscope (SEM) image of biochar

\subsection{XRD spectrum analysis of biochar}

Fig. 6 characterizes the XRD spectrum of corncob biochar prepared by different pyrolysis devices at different pyrolysis temperatures. It can be seen from the diagram that there are two obvious characteristic peaks of cellulose at $15.3^{\circ}$ and $22.3^{\circ}$ before pyrolysis[14]. When the corncob was pyrolyzed at $250^{\circ} \mathrm{C}$, the biochar obtained from muffle furnace and solar pyrolysis device still maintained the characteristic peak of cellulose, while the structure of cellulose from vacuum tube furnace was destroyed and the carbonization was more obvious, while the characteristic peak of cellulose disappeared at $300^{\circ} \mathrm{C}$, and the characteristic peak of $\mathrm{KCl}$ appeared at $28.2^{\circ}$ and $40.4^{\circ}$ for each pyrolysis mode. At $350^{\circ} \mathrm{C}$, the characteristic peak of boron nitride appeared at $26.8^{\circ}$ for biochar from vacuum tube furnace, and the characteristic peak of $\mathrm{KCl}$ was maintained at $28.2^{\circ}$ and $40.4^{\circ}$ for the other two pyrolysis methods. 


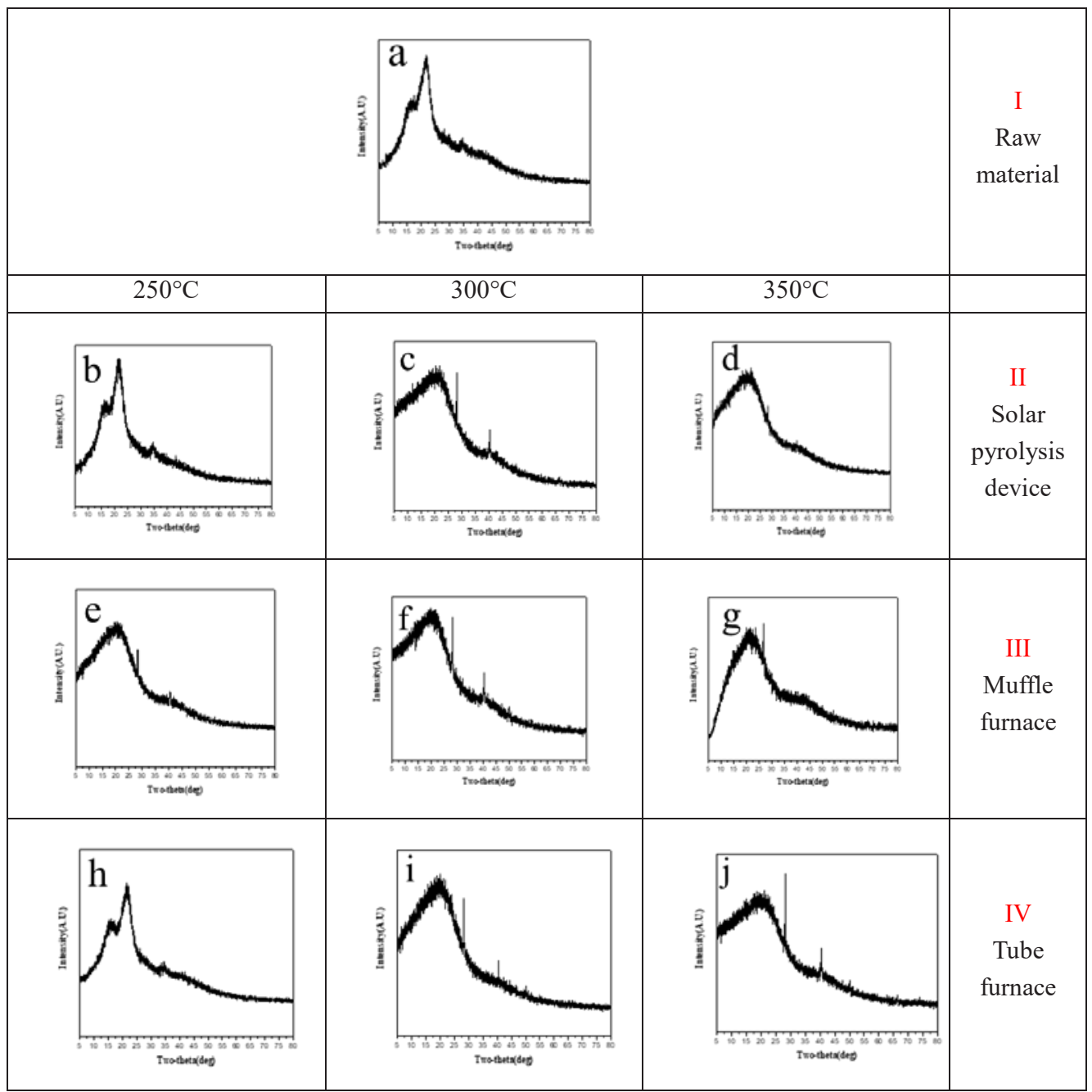

Fig.5. XRD graphs of biochar prepared by different equipment at different temperatures

\subsection{FTIR analysis of biochar}

Fig.7 shows the infrared spectrum of biochar obtained from corncob at different pyrolysis temperatures by using different pyrolysis devices. As can be seen from the diagram, when $3361 \sim 3385 \mathrm{~cm}^{-1}$ is- $\mathrm{OH}$, the intensity of this peak decreases with the increase of temperature, the dehydration of biomass at high temperature weakens the surface-OH of biochar, the absorption peak of $\mathrm{C}=\mathrm{H}$ of polymer fatty carbon chain is at $2918 \sim 2925 \mathrm{~cm}^{-1}$, and the vibration peak of $\mathrm{C}=\mathrm{O}$ is at $1696 \mathrm{~cm}^{-1}$, and the intensity of this peak does not change obviously with pyrolysis temperature. The intensity of C-O-C characteristic peak of aliphatic group at $1053 \mathrm{~cm}^{-1}$ decreases obviously with the increase of temperature, which indicates that $\mathrm{C}-\mathrm{O}-\mathrm{C}$ bond is easy to break during pyrolysis. The infrared spectra of biochar obtained by three pyrolysis methods have similar rules, and the infrared spectra of biochar obtained by solar pyrolysis device and muffle furnace pyrolysis are more similar. 

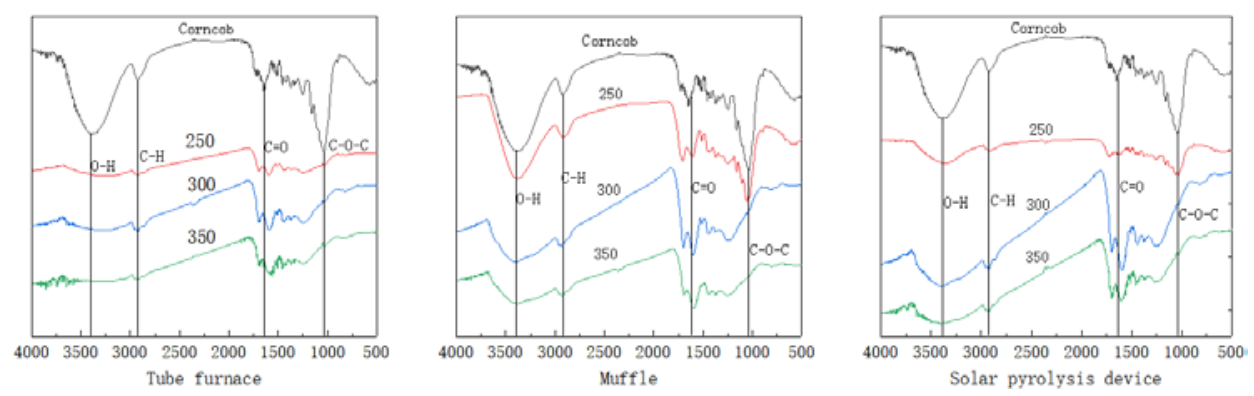

Fig.6. The FTIR spectra for the biochar prepared at different pyrolysis conditions

\section{Conclusion}

Experiment shows that the solar pyrolysis device can reach $250^{\circ} \mathrm{C}-400^{\circ} \mathrm{C}$ in different seasons, which is in line with the temperature required for the main stage of biomass pyrolysis, and the optical microstructure of biochar prepared by three pyrolysis methods is similar, and it has been completely carbonized at $350^{\circ} \mathrm{C}$. With the increase of pyrolysis temperature, the yield of biochar from the three devices decreases, and the change range of biochar yield from solar pyrolysis device and muffle furnace is similar. In addition, the analysis of FTIR and XRD spectroscopy also shows that the surface structure and physical and chemical properties of solar pyrolysis biochar are similar to those of muffle furnace pyrolysis. Therefore, it is feasible to use solar pyrolysis of biomass.

\section{Acknowledgements}

This work was supported by the Guangdong College Students' Innovative Project (pdjh2021b0538, X201910580158) and the Technology Innovation Project of Zhaoqing (201904030103).

\section{References}

[1] Li W, Gao P. Biomass Energy and Sustainable Development. Northern Environment 2013;25:4-7.

[2] Bi Y, Gao C, Wang Y, Li B. Estimation of straw resources in China. Transactions of the Chinese Society of Agricultural Engineering 2009;25:211-217.

[3] Zhang L, Xue D, Li G, Hou S. Straw Mixed Combustion Characteristics and Kinetic Analysis. Transactions of The Chinese Society of Agricultural Machinery 2014;45:202-206.

[4] Lv X, Xinuerxaiti•Zhumaxi, Lu X. Present situation and development prospect of straw returning technology in China. Modernizing Agriculture 2004:41-42.

[5] Huo L, Zhao L, Meng H, Rao Z. Study on straw multi-use potential in China. Transactions of the Chinese Society of Agricultural Engineering 2019;35:218-224.

[6] Sun A, Yang P, Ding L, Liu J. Research progress of straw feed development and utilization technology. Jiangxi Feed 2011:31-33.

[7] Yingqun M, Yanqing S, Yu L, Baihe H. State of the art of straw treatment technology: Challenges and solutions forward. Journal of Chinese Agricultural Mechanization 2020;41:152-161. 
[8] Dong X, Xu C, Zhu Q, Chen Y, Gao Q, Wang X. Research Progress on the Effects of Straw Returning to the Field on Soil Environment. Journal of Anhui Agricultural Sciences 2020;48:1-4.

[9] Ni S, Zang X, Deng Y, Xue M, Lu S, Ren B. Research and application prospect of straw biogas technology. Jiangsu Agricultural Sciences 2010:458-459.

[10]Kambo HS, Dutta A. A comparative review of biochar and hydrochar in terms of production, physico-chemical properties and applications. Renewable and Sustainable Energy Reviews 2015;45:359-378.

[11]Liubiao, Chen Y, Hetao, Haiping Y, Xianhua W, Hanping C. Application of cogeneration technology of gas-liguid-soild products pyrolyzed from crop straw. Transactions of the Chinese Society of Agricultural Engineering 2013;29:213-219.

[12]Chang Q, Du Y, Dai M, Lin D, Peng C. Biochar prepared by solar pyrolysis and its adsorption of copperions in water. Chinese Journal of Environmental Engineering 2020;14:2946-2958.

[13]Wu D, Chen C, Hou X, Sun K. Effect of Pyrolysis Temperature on Structures of Chars Forming from Cellulose and Lignin. Biomass Chemical Engineering 2021;55:1-9.

[14]Wei H, Li D, Ma J, Zhou D, Cui D. Journal of Lanzhou University of Technology 2020;46:77-84. 